\title{
EFFECT OF CALCIUM HYDROXIDE CHLORHEXIDINE MIX ON PULPECTOMIZED ANTERIOR PRIMARY TEETH (CLINICAL AND RADIOGRAPHICAL STUDY)
}

\author{
Islam M Shindy*, Ibrahim F. Barakat*, Tamer Abdellatif Elmansy**, Amani M. Tawfik ${ }^{* * *}$
}

\begin{abstract}
Objective: The objective was to evaluate effect of Calcium Hydroxide Chlorhexidine mix on pulpectomised primary anterior teeth microbiologically, clinically and radiographically (immediately one month and three months). Subjects \& Methods: The sample size was estimated to be 32 randomly selected Egyptian children were divided into two equal groups: Group A: Irrigated with sodium hypochlorite $(\mathrm{n}=16)$. Group B: Irrigated with calcium hydroxide chlorhexidine mix (CH-CHX) $(\mathrm{n}=16)$. A fresh sample was collected from each root canal before and two days after irrigation by the help of paper point. Then the sample was added to a tube containing $9 \mathrm{ml}$ Amies medium as a transfer medium to keep the viability of the microorganisms under aseptic condition. 16 teeth were obturated with zinc oxide eugenol obturating material and another 16 teeth were obturated with calcium hydroxide chlorhexidine mix obturating material.All samples were transferred to the bacteriological laboratory at Faculty of medicine, Al-Azhar University - (Cairo -girls) for culture on the selective media and quantification of E. faecalis colony forming units (CFUs).All samples were followed clinically and radiographically immediately after obturation, one month and three months, the sign of success and failure were recorded.The number of $\mathrm{E}$. faecalis colonies before and after irrigation was compared for each group. Results: It was found that the number of E.faecalis colonies were decreased in all groups, But these differences were statistically insignificant. Conclusion: From the results of this study we can be concluded that: 1 . Both 5\%mm sodium hypochlorite and calcium hydroxide chlorhexidine mix irrigant solutions have antibacterial effect against E.faecallis. 2. Calcium hydroxide chlorhexidine mix irrigant solution was superior to $0.5 \%$ sodium hypochlorite when used against E.faecalis bacteria but the difference between them was non-significant.3.No effect in different obturating materials in success or failure.
\end{abstract}

KEY WORDS: Calcium hydroxide, Chlorhexidine, E.faecalis .

\section{INTRODUCTION}

Microbial invasion of the root canal system has an important role in initiating and sustaining periapical disease. The aim of root canal therapy is to eliminate bacteria and their by-products from the root canal system. Although Chemomechanical cleaning and shaping of the canal is effective in reducing bacterial counts, microorganisms may persist in the anatomical complexities of root canal system and increase the risk of treatment failure. Therefore, intracanal medication is advocated to further reduce bacteria in the root canal system and increase the success of root canal treatment.

A number of microorganisms can produce enough acid to demineralize tooth structure, particularly aciduric streptococci, lactobacilli, diphtheroid yeasts, staphylococci, and certain strains of sarcinae. Streptococcus mutans has been

- B.D.S (2007), Faculty of Dental Medicine,Al-Azhar University. Demonstrator, Department of Pedodontics and Oral Health, Faculty of Dental Medicine,Al-Azhar University (Assiut Branch)

* Assistant Professor of Pedodontic and Oral Health, Faculty of Dental Medicine, Boys, Cairo, Al Azhar University

** Lecture of Pedodontic and Oral Health, Faculty of Dental Medicine,Boys, Cairo, Al Azhar University.

*** Professor of Pedodontic and Oral Health, Faculty of Medicine, Girls, Al Azhar University 
implicated as one of the major and most virulent of the caries-producing organisms.

When dental caries invade the pulp tissues and it was necessary to treat the tooth endodontically, the essential for endodontic success is to eliminate or at least reduce the number of microorganisms and remove inflamed or necrotic pulpal tissue.

Irrigants should ideally have antimicrobial and tissue-dissolution actions as well as other advantageous properties, such as lubrication, demineralization, and the ability to remove debris and the smear layer.

The most common Irrigants used during root canal preparation is sodium hypochlorite $(\mathrm{NaOCl})$. It is an effective tissue solvent and has excellent antimicrobial property, ${ }^{(1)}$ however, its tissue toxicity, corrosive effect on endodontic instruments, and disagreeable odor have to be of concern ${ }^{(2)}$.

Also Chlorhexidine digluconate (CHX) has been suggested as an irrigant in endodontic treatment because its antimicrobial activity however, its inability to dissolve organic matter is a drawback in its clinical use ${ }^{(3)}$. Other irrigant materials had been widely used as alcohol, hydrogen peroxide, ethylenediaminetetraacetic acid (EDTA)

Calcium hydroxide $(\mathrm{CH})$ consider the most commonly used intracanal medicament in endodontics ${ }^{(4)}$. In selecting an irrigant and technique, consideration must be given to their efficacy and safety.

Many studies have attempted to compare antibacterial effect of $\mathrm{CH}$ alone or in combination with CHX. Some studies have shown an increased antibacterial effect when $\mathrm{CHX}$ is added to $\mathrm{CH}(5,6)$, while other studies show that no benefits ${ }^{(7)}$. It seems that the usefulness of mixing $\mathrm{CH}$ with $\mathrm{CHX}$ remains unclear and controversial ${ }^{(8)}$. Therefore, the aim of this study was to evaluate the effect of $\mathrm{CHX}-\mathrm{CH}$ mix Enterococcus faecalies (E faecalies) compared with sodium hypochlorite.

\section{PATIENTS, MATERIALS AND METHODS}

Study design: prospective, clinical study.

The study was carried out 32 randomly selected Egyptian children from the Pedodontics Outpatient Clinic, Faculty of Dental Medicine, Al-Azhar University with age was ranged from 3 to 6 years. The children and their parents were informed about the purpose of the study and an informed consent document prior to participation was signed.

\section{Inclusion criteria}

1. Children in the age group of three to five years irrespective of gender.

2. Decayed anterior teeth with or without periapical pathosis.

3. Patients without systemic diseases.

4. Patients who did not report the use of antibiotics for at least three months prior to the_treatment

\section{Exclusion Criteria}

1. Patients with systemic diseases and immunologically compromised conditions.

2. Patients on antibiotic therapy within three months prior to the study.

3. Teeth with external or internal resorption.

4. Teeth with previous intracanal therapy.

When patients met the inclusion criteria of the study, the treatment procedure was explained in their own language and an informed consent was obtained from their parents

\section{Children were divided into 2 equal groups:}

Group A:16 non-vital anterior teeth irrigated with $0.5 \%$ sodium hypochlorite and obturated with zinc oxide eugenol.

Group B: 16 non-vital anterior teeth irrigated with calcium hydroxide Chlorhexidine mix solution -and obturated with calcium hydroxide chlorhexidine mix 


\section{Procedures}

After anesthesia and isolation with a rubber dam, Access cavity was gained on the palatal surface of each tooth using sterile round bur No 2 or No 4 and long tapering diamond point in a high-speed hand piece with water coolant. Then the working length was then determined with (\# $25 \mathrm{~K}$ or \#30K) stainless steel file and confirmed with the radiograph and NSK apex locator (Figure 1).

The first microbiological sample (control S1) was collected by introducing a sterile paper point with a diameter compatible with that of the canal.

Chemomechanical Preparation: Sterile Universal $\mathrm{K}$ files were used for mechanical preparation of the canal.

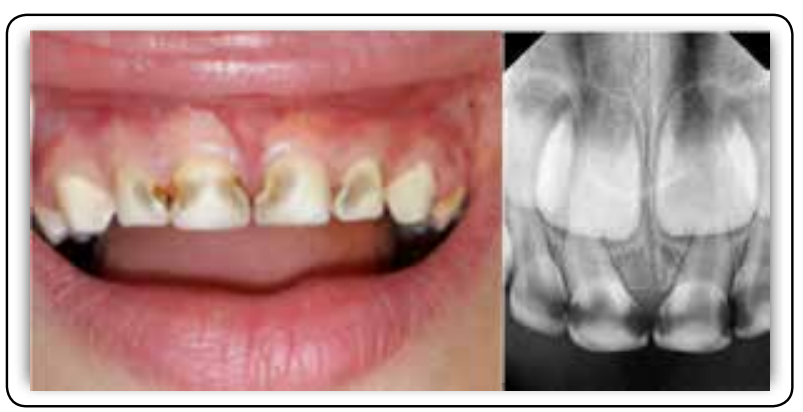

FIG (1) Preoperative intraoral image and X-ray

\section{Irrigation}

Two types of irrigant solutions were used in this study sodium hypochlorite and calcium hydroxide chlorohexidine mix.

The CHX (2\% Gluco-hex solution Poland) was mixed with sterile $\mathrm{Ca}(\mathrm{OH}) 2$ powder (JK India) until smooth slurry was formed.

The prepared canals were flushed with $5 \mathrm{ml}$ of one of the following irrigant solutions as a final rinse:

Group A: $0.5 \%$ sodium hypochlorite for 3 minutes.

Group B: calcium hydroxide chlorhexidine mix for 3 mins.
Plastic syringes of different sizes are used for irrigation as large volume syringes potentially are more difficult to control for pressure and accidents may occur. Therefore, to maximize safety and control, use of 1 to $5 \mathrm{~mL}$ syringes with side vented needles is recommended instead of the larger ones with conventional needles.

Separate syringes were used for each solution Because of the chemical reactions between many irrigants. Smaller needle sizes are preferred (27 -30Gauge needle) to facilitate effectiveness and minimize safety risks. The needle should remain loose inside the canal to allow the irrigant to reflux and causes more debris to be displaced coronally. At the same time needle is moved up and down in the canal to enhance mechanical action.

The treated canals were sealed with temporary sealing material. If the treated tooth was badly decayed and not retentive for temporary filling, it will be sealed temporary by glass ionomer filling.

After 48 hours the temporary sealing (glass ionomer) was removed and the second sample was collected as done previously.

\section{Obturation}

Obturation was performed with two types of obturating materials as the following:

Group A: obturated with zinc oxide and eugenol.

Group B: obturated with calcium hydroxide chlorhexidine mix

\section{Procedure of obturation}

After removal of temporary sealing (glass ionomer) all thirty-two teeth irrigated with the normal saline then irrigated with sodium hypochlorite for three minutes then irrigated by normal saline and finally sealed with temporary filling or glass ionomer.

After forty-eight hours the temporary filling or glass ionomer was removed and irrigated with 
normal saline then sodium hypochlorite then normal saline and dried.

All dried canals for group A obturated with zinc oxide eugenol while the canals of group B obturated with calcium hydroxide chlorhexidine mix.

The treated teeth were sealed as done previously, in the later appointments followed by composite resin as a final restoration (Figure 2).

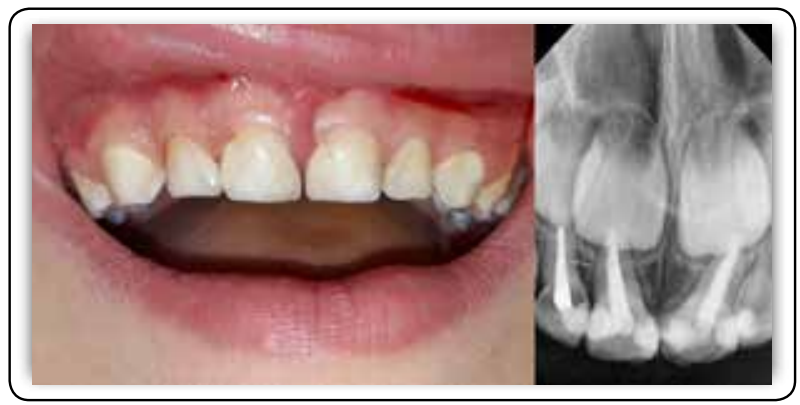

FIG (2) Post-operative image and x-ray

\section{Microbiological evaluation:}

The microbiological samples $(\mathrm{S} 1, \mathrm{~S} 2)$ are collected from the root canal of pulpectomised primary anterior teeth using sterile paper point. Samples were preserved in $2 \mathrm{ml}$ peptone water liquid media as transfere media to keep the viability of E.Faecalis under complete a septic condition.All specimens were transported as soon as possible to microbiologicl lab at Microbiology Department, Faculty of Medicine, Girls, Al-Azhar University for culture procedure on selective media.

The E. faecalis used in this study was prepared by growing Pure E. faecalis on a bile-osculin plate for 24 hours at $37^{\circ} \mathrm{C}$, the purity of the culture was confirmed by culture characteristics, microscopic examination and biochemical reactions.

\section{1- Culture characteristics:}

Primary identification was done by colony morphology using bile osculin media, the colonies of E. Faecalis Change the transparent media into black

\section{2- Microscopic examination:}

The colonies of E.Faecalis were subjected to Gram's staining, colonies were picked up by bacteriological loop and emulsified in a drop of water on a clean slide, then after dryness and heat fixation they were stained by crystal violet, iodine solution and carbol fuchin, the stained smear was examined under oil emersion lens at 100x magnification, the E.Faecalis appeared as $\mathrm{G}+\mathrm{Ve}$ cocci in ovoid pairs and short chain.

\section{Observations}

The teeth were observed clinically and radiographically through the periods of this study immediately, after 1 month and after three months:

\section{1- Clinical criteria}

The criteria for clinical success were that patients were completely free of clinical signs and symptoms including pain, gingival abscesses, fistula openings, and abnormal mobility ${ }^{(9)}$.

\section{2 - Radiographic criteria}

No evidence of bone or root resorption, except for that associated with the exfoliation process.

Pathological resorption associated with bone rarefaction; follow-up in six months.

Pathological resorption associated with bone rarefaction; extract immediately.

Periapical radiolucencies that remained unchanged were not regarded as failure.

If any item in the previously mentioned criteria of success was not fulfilled, the case was considered failure

\section{Ethical consideration}

The research Protocol is approved by the ethical committee, Faculty of Dental Medicine, AL-Azhar University. 


\section{Data management and Statistical analysis:}

The data were collected, tabulated and statistically analyzed using software SPSS program (Statistical Package for Social Sciences).

\section{RESULTS}

\section{Antibacterial results:}

\section{A-Relation between S1 and S2:}

\section{1- Group A (irrigation by sodium hypochlorite)}

There was a statistically significant difference between $(\mathrm{S} 1)$ and $(\mathrm{S} 2)$ groups where $(\mathrm{p}<0.001)$.

The highest mean bacterial value was found in $\mathrm{S} 1$ while the lowest mean bacterial value was found in S2(Table 1).

TABLE (1) Antibacterial activity of sodium hypochlorite

\begin{tabular}{|c|c|c|}
\hline \multirow{2}{*}{ Variables } & \multicolumn{2}{|c|}{ Bacterial reduction } \\
\cline { 2 - 3 } & Mean & SD \\
\hline After irrigation by sodium hypochlorite & $72.40 \%$ & 16.93 \\
\hline p-value & \multicolumn{2}{|c|}{$0.071 *$} \\
\hline
\end{tabular}

2- Group B (irrigation by calcium hydroxide chlorhexidine mix)

There was a statistically significant difference between (S1) and (S2) groups where ( $\mathrm{p}=0.025)$.

The highest mean bacterial value was found in $\mathrm{S} 1$ while the lowest mean bacterial value was found in S2(Table 2).

TABLE (2) Antibacterial activity of calcium hydroxide chlorhexidine mix

\begin{tabular}{|c|c|c|}
\hline \multirow{2}{*}{ Variables } & \multicolumn{2}{|c|}{ Bacterial reduction } \\
\cline { 2 - 3 } & Mean & SD \\
\hline $\begin{array}{c}\text { After irrigation by calcium } \\
\text { hydroxide chlorhexidine mix }\end{array}$ & $76.93 \%$ & 21.27 \\
\hline p-value & \multicolumn{2}{|c|}{$* 0.071$} \\
\hline
\end{tabular}

\section{3- Relation between different groups:}

There was a statistically insignificant difference between (After irrigation by sodium hypochlorite) and (After irrigation by calcium hydroxide chlorhexidine mix) groups where $(\mathrm{p}=0.071)$.

The higher mean bacterial reduction was found in (After irrigation by calcium hydroxide chlorhexidine mix) group, while the lowest mean bacterial reduction was found in (After irrigation by sodium hypochlorite) group (Table3, Figure 3).

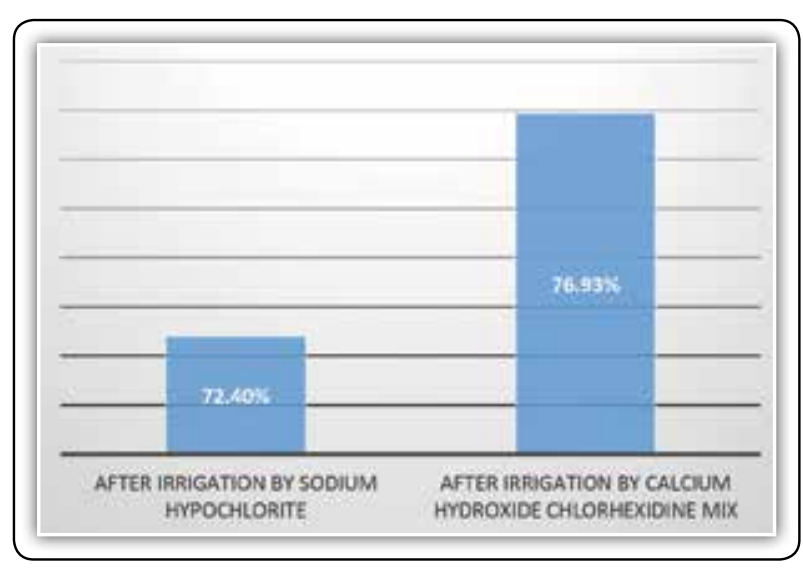

FIG (3) Relation between different groups

TABLE (3) The mean, standard deviation (SD) values of percentage of bacterial reduction of different groups

\begin{tabular}{|c|c|c|}
\hline \multirow{2}{*}{ Variables } & \multicolumn{2}{|c|}{ Bacterial reduction } \\
\cline { 2 - 3 } & Mean & SD \\
\hline $\begin{array}{c}\text { After irrigation by sodium } \\
\text { hypochlorite }\end{array}$ & $72.40 \%$ & 16.93 \\
\hline $\begin{array}{c}\text { After irrigation by calcium } \\
\text { hydroxide chlorhexidine mix }\end{array}$ & $76.93 \%$ & 21.27 \\
\hline p-value & \multicolumn{2}{|c|}{$0.071 *$} \\
\hline
\end{tabular}

\section{Clinical and radiographic evaluation:}

\section{Group A :}

Sixteen teeth in this group received zinc oxide eugenol obturation material. It was found that 13 teeth $(81 \%)$ of the group were treated positively 
with zinc oxide eugenol obturation and appear normal as evaluated and measured by clinical and radiographic assessments for 3 successive months While the remaining 3 teeth (19\%) failed to responded positively. For this reason, extraction was performed for them (Table 4).

TABLE (4) Clinical radiographic evaluation

\begin{tabular}{|l|c|c|c|}
\hline & $\begin{array}{c}\text { Post- } \\
\text { operative }\end{array}$ & 1 Month & 3 Months \\
\hline Pain & 0 & 2 & 3 \\
\hline Swelling & 0 & 2 & 3 \\
\hline Mobility & 0 & 0 & 0 \\
\hline Sinus tract & 0 & 0 & 0 \\
\hline Periapical radiolucency & 0 & 1 & 2 \\
\hline Periodontal space & 0 & 1 & 1 \\
\hline Internal and external resorption & 0 & 0 & 0 \\
\hline
\end{tabular}

There was no statistically significant difference between (1month) and (3months) groups where $(\mathrm{p}=0.157)$.

After 1 month, 14 (87.5\%) cases showed success and $2(12.5 \%)$ cases failed, while after 3 months, $13(81 \%)$ cases showed success and $3(19 \%)$ cases failed.

\section{Group B}

Sixteen teeth in this group received calcium hydroxide chlorhexidine mix obturation material. It was found that 12 teeth $(75 \%)$ of the group were treated positively with calcium hydroxide chlorhexidine mix obturation and appear normal as evaluated and measured by clinical and radiographic assessments for 3 successive months While the remaining 4 teeth (25\%) failed to responded positively. For this reason, extraction was performed for them (Table 5).
TABLE (5) Failure mode after 3 months in group B

\begin{tabular}{|l|c|c|c|}
\hline & $\begin{array}{c}\text { Post-op- } \\
\text { erative }\end{array}$ & 1 Month & 3 Months \\
\hline Pain & 0 & 2 & 4 \\
\hline Swelling & 0 & 2 & 4 \\
\hline Mobility & 0 & 0 & 0 \\
\hline Sinus tract & 0 & 0 & 0 \\
\hline Periapical radiolucency & 0 & 1 & 2 \\
\hline Periodontal space & 0 & 1 & 1 \\
\hline Internal and external resorption & 0 & 0 & 0 \\
\hline
\end{tabular}

There was no statistically significant difference between (1month) and (3months) groups where $(\mathrm{p}=0.564)$.

After 1 month, 14 (87.5\%) cases showed success and $2(12.5 \%)$ cases failed, while after 3 months, $12(75 \%)$ cases showed success and $4(25 \%)$ cases failed.

\section{Effect of obturating material:}

After 1 month: There was no statistically significant difference between (Group A) and (Group B) groups where $(\mathrm{p}=1)$.

Both; Group A and Group B showed 2 (12.5\%) cases showed success and $14(87.5 \%)$ cases failed.

After 3 months: There was no statistically significant difference between (Group A) and (Group B) groups where $(\mathrm{p}=0.674)$.

Group A, 13 (81\%) cases showed success and 3 (19\%) cases failed, while for Group B, 12 (75\%) cases showed success and $4(25 \%)$ cases failed (Table 6, Figure 4). 


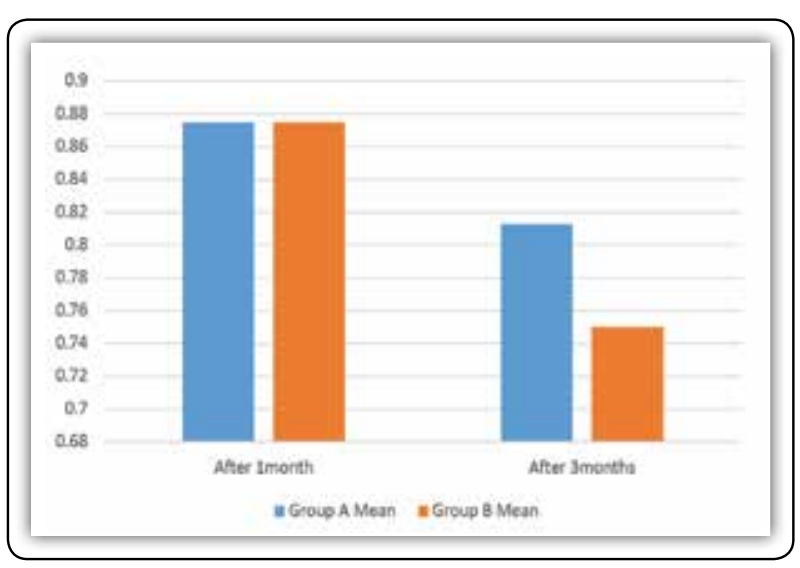

FIG (4) Values of failure mode of different groups

TABLE (6) The mean, standard deviation (SD) values of failure of different groups.

\begin{tabular}{|c|c|c|c|c|c|}
\hline \multirow{2}{*}{ Variables } & \multicolumn{4}{|c|}{ Failure mode } \\
\cline { 2 - 5 } & \multicolumn{2}{|c|}{ Group A } & \multicolumn{2}{c|}{ Group B } & \multirow{2}{*}{ P-value } \\
\cline { 2 - 5 } & Mean & SD & Mean & SD & \\
\hline $\begin{array}{c}\text { After } \\
\text { 1month }\end{array}$ & 0.875 & 0.342 & 0.875 & 0.342 & $1 \mathrm{~ns}$ \\
\hline $\begin{array}{c}\text { After } \\
\text { 3months }\end{array}$ & 0.813 & 0.403 & 0.750 & 0.447 & $0.674 \mathrm{~ns}$ \\
\hline \begin{tabular}{c} 
p-value \\
\hline
\end{tabular} & $0.564 \mathrm{~ns}$ & \multicolumn{2}{|c|}{$0.157 \mathrm{~ns}$} & \\
\hline
\end{tabular}

*; significant $(p<0.05)$ ns; non-significant $(p>0.05)$

\section{DISCUSSION}

In this study, the microbial investigations exhibited anaerobic microorganism in the infected root canals mainly enterococcus fecalis this was seen through decrease in there count after irrigation with $0.5 \%$ sodium hypochlorite by $72.4 \%$. this result is in concomitant with other restudies.

In study of Berber et al ${ }^{(10)}$ assessed the efficacy of $0.5 \%, 2.5 \%$ and $5.25 \% \mathrm{NaOCl}$ as intracanal irrigants against E. faecalis within root canals and dentinal tubules, they found that $5.25 \%$ concentration was the most effective solution followed by $2.5 \%$ concentration.
Another investigator, ${ }^{(11)}$ compared the efficacy of two different concentrations of $\mathrm{NaOCl}(5.25 \%$ and $1.5 \%$ ) with $2 \%$ chlorhexedine (CHX) gel against E. faecalis, they concluded that $5.25 \% \mathrm{NaOCl}$ and $2 \%$ CHX gel had good potential to keep a low E. faecalis count immediately and 7 days after instrumentation, where as $1.5 \% \mathrm{NaOCl}$ reduced the E. faecalis only after instrumentation.

The antimicrobial effectiveness of sodium hypochlorite, based in its high $\mathrm{pH}>11$ (hydroxyl ions action), is similar to the mechanism of action of calcium hydroxide. The high $\mathrm{pH}$ of sodium hypochlorite interferes in the cytoplasmic membrane integrity with an irreversible enzymatic inhibition, biosynthetic alterations in cellular metabolism and phospholipid degradation observed in lipidic peroxidation ${ }^{(12)}$. The amino acid chloramination reaction forming chloramines interfere with cellular metabolism. Oxidation promotes irreversible bacterial enzymatic inhibition replacing hydrogen with chlorine. This enzyme inactivation can be observed in the reaction of chlorine with amino groups (NH2-) and an irreversible oxidation of sulphydryl groups (SH) of bacterial enzymes (cystein). Thus, sodium hypochlorite presents antimicrobial activity with action on bacterial essential enzymatic sites promoting irreversible inactivation originated by hydroxyl ions and chloramination action. Dissolution of organic tissue can be verified in the saponification reaction when sodium hypochlorite degrades fatty acids and lipids resulting in soap and glycerol ${ }^{(12)}$.

In this present study the reduction of the number of E. Faecalis bacterial colony before and after irrigation; for calcium hydroxide chlorhexidine mix solution was $76.9 \%$.

Combined use of $\mathrm{CHX}$ and $\mathrm{Ca}(\mathrm{OH}) 2$ in the root canal may generate excessive reactive oxygen species, which may potentially kill various root canal pathogens ${ }^{(13)}$. Furthermore, it has been demonstrated that the alkalinity of $\mathrm{Ca}(\mathrm{OH}) 2$ when mixed with $\mathrm{CHX}$ remained unchanged ${ }^{(14)}$. 
In a study by Almyroudi et al., all of the CHX formulations used, including a $\mathrm{CHX} / \mathrm{CH}$ 50:50 mix, were efficient in eliminating E. faecalis from the dentinal tubules with a $1 \%$ CHX gel working slightly better than the other preparations ${ }^{(15)}$. These findings were corroborated by Gomes et al ${ }^{(16)}$. in bovine dentine and Schafer and Bossmann in human dentine where 2\% CHX gel had greater activity against $\mathrm{E}$. faecalis, followed by $\mathrm{CHX} / \mathrm{CH}$ and then $\mathrm{CH}$ used alone.

In a study using agar diffusion, researchers could not demonstrate any additive antibacterial effect by mixing $\mathrm{CH}$ powder with $0.5 \% \mathrm{CHX}$ and they showed that the $\mathrm{CHX}$ had a reduced antibacterial action ${ }^{(14)}$. However, $\mathrm{CH}$ did not lose its antibacterial properties in such a mixture. This may be due to the deprotonation of $\mathrm{CHX}$ at a $\mathrm{pH}$ greater than 10 , which reduces its solubility and alters its interaction with bacterial surfaces as a result of the altered charge of the molecule. In an in vitro study using human teeth, Ercan et al ${ }^{(6)}$. showed $2 \%$ CHX gel was the most effective agent against $\mathrm{E}$. faecalis inside dentinal tubules, followed by a $\mathrm{CH} / 2 \% \mathrm{CHX}$ mix, whilst $\mathrm{CH}$ alone was totally ineffective, even after 30 days. The $2 \% \mathrm{CHX}$ gel was also significantly more effective than the $\mathrm{CH} / 2 \% \mathrm{CHX}$ mix against C. albicans at seven days, although there was no significant difference at 15 and 30 days. $\mathrm{CH}$ alone was completely ineffective against C. albicans. These results were further validated by another in vivo study using primary teeth. A $1 \% \mathrm{CHX}$ gluconate gel, both with and without $\mathrm{CH}$, was more effective against $\mathrm{E}$. faecalis than $\mathrm{CH}$ alone over a 48-hour period ${ }^{(17)}$.

The results of the present study showed that two visit pulpectomy with ZOE as root canal filling material was successful in $81 \%$ of the teeth treated as verified by clinical and radiographic examinations, Successful pulpectomies was clinically asymptomatic and radiographically reduced or not changed the radiolucency before the treatment. This result was agreement with other studies ${ }^{(18,19)}$.

According to other studies, the success rate of ZOE was $83.3 \%$ and $88.6 \%$ in follow up periods of 6 and 9 months respectively. $(20,21)$ And in a systematic review the overall success rate of $\mathrm{ZOE}$ was between $80-100 \%{ }^{(18)}$.

Other study revealed that; high success rate of ZOE may be due to the beneficial effects of eugenol, The amount of eugenol released in the periapical zone immediately after placement is 10 4 , and it falls to $10-6$ after $24 \mathrm{~h}$ and reaches zero after 1 month. In these concentrations, eugenol is said to have anti-inflammatory and analgesic properties that are very useful after a pulpectomy procedure. While the low percentage of failure rate of ZOE paste as obturating material in badly decayed primary anterior teeth during pulpectomy procedure was $10 \%$, due to drawbacks of ZOE such as slow rate of resorption, irritation to the periapical tissues, necrosis of bone and cementum, and alters the path of eruption of succedaneous tooth.

The results of the present study showed that two visit pulpectomy with calcium hydroxide chlorhexidine mix as root canal filling material was successful in $75 \%$ of the teeth treated as verified by clinical and radiographic examinations, Successful pulpectomies was clinically asymptomatic and radiographically reduced or not changed the radiolucency before the treatment.

The greatest difference in the antibacterial activity of $\mathrm{CH} / \mathrm{CHX}$ and $\mathrm{CH}$ groups has been reported in the study performed by Delgado, et al ${ }^{(5)}$. This might be due to longer dressing period, sample size, type and concentration of CHX compared with other studies.

The lower percent of success rate of calcium hydroxide chlorhexidine mix obturating material can be explained due to deprotonation of $\mathrm{CHX}$ at high $\mathrm{pH}$, which reduces its solubility and alters its 
interaction with bacterial surfaces as a result of the altered charge of the molecule ${ }^{(22)}$.

In conclusion it appears that mixing $\mathrm{CH}$ with CHX does not improve its antibacterial property as an intracanal medicament against E. faecalis. Further in vivo studies are necessary to correlate this result.

\section{CONCLUSIONS}

From the results of the present study, the following conclusions could be drawn:

1. Calcium hydroxide chlorhexidine mix irrigant solution was superior to $0.5 \%$ sodium hypochlorite when used against E.faecalis bacteria and the difference between them is non-significant.

2. Obturation with Calcium hydroxide chlorhexidine mix give lower success rate values compared to obturation with zinc oxide eugenol.

\section{REFERENCES}

1. Leonardo M, Tanomaru Filho M, Nelson Filho P, Bonifácio $\mathrm{K}$, Ito I. In vivo antimicrobial activity of $2 \%$ chlorhexidine used as a root canal irrigating solution. Journal of Endodontics. 1999;25(3):167-71.

2. Peters OA, Roehlike JO, Baumann MA. Effect of immersion in sodium hypochlorite on torque and fatigue resistance of nickel-titanium instruments. Journal of Endodontics. 2007;33(5):589-93.

3. Hong S-T, Bae K-S, Baek S-H, Kum K-Y, Shon W-J, Lee W. Effects of root canal irrigants on the push-out strength and hydration behavior of accelerated mineral trioxide aggregate in its early setting phase. Journal of endodontics. 2010;36(12):1995-9.

4. Siqueira Jr J, Lopes HJIej. Mechanisms of antimicrobial activity of calcium hydroxide: a critical review. 1999;32(5):361-9.

5. Delgado RJ, Gasparoto TH, Sipert CR, Pinheiro CR, Moraes IG, Garcia RB, et al. Antimicrobial effects of calcium hydroxide and chlorhexidine on Enterococcus faecalis. 2010;36(8):1389-93.
6. Ercan E, Dalli M, Dülgergil ÇTJOS, Oral Medicine, Oral Pathology, Oral Radiology,, Endodontology. In vitro assessment of the effectiveness of chlorhexidine gel and calcium hydroxide paste with chlorhexidine against Enterococcus faecalis and Candida albicans. 2006; 102(2):e27-e31.

7. Lynne RE, Liewehr FR, West LA, Patton WR, Buxton TB, McPherson III JCJJoe. In vitro antimicrobial activity of various medication preparations on $\mathrm{E}$. faecalis in root canal dentin. 2003;29(3):187-90.

8. Pereira TC. Descontaminação intra-tubular de dentes bovinos por pastas de hidróxido de cálcio associadas a diferentes veículos: Universidade de São Paulo; 2015.

9. Fuks A, Eidelman E, Pauker NJJoCPD. Root fillings with Endoflas in primary teeth: a retrospective study. 2003;27(1):41-5.

10. Berber V, Gomes B, Sena N, Vianna M, Ferraz C, Zaia A, et al. Efficacy of various concentrations of $\mathrm{NaOCl}$ and instrumentation techniques in reducing Enterococcus faecalis within root canals and dentinal tubules. 2006;39(1): 10-7.

11. Oliveira DP, Barbizam JV, Trope M, Teixeira FBJOS, Oral Medicine, Oral Pathology, Oral Radiology,, Endodontology. In vitro antibacterial efficacy of endodontic irrigants against Enterococcus faecalis. 2007;103(5):702-6.

12. Estrela C, Estrela CR, Barbin EL, Spanó JCE, Marchesan MA, Pécora JDJBdj. Mechanism of action of sodium hypochlorite. 2002;13(2):113-7.

13. Yeung S, Huang C, Chan C, Lin C, Lin H, Lee P, et al. Antioxidant and pro-oxidant properties of chlorhexidine and its interaction with calcium hydroxide solutions. 2007;40(11):837-44

14. Zehnder M, Grawehr M, Hasselgren G, Waltimo TJOS Oral Medicine, Oral Pathology, Oral Radiology,, Endodontology. Tissue-dissolution capacity and dentin-disinfecting potential of calcium hydroxide mixed with irrigating solutions. 2003;96(5):608-13.

15. Almyroudi A, Mackenzie D, McHugh S, Saunders WJJoE. The effectiveness of various disinfectants used as endodontic intracanal medications: an in vitro study. 2002; 28(3):163-7 
16. Schäfer E, Bössmann KJJoE. Antimicrobial efficacy of chlorhexidine and two calcium hydroxide formulations against Enterococcus faecalis. 2005;31(1):53-6.

17. Önçä̈ Ö, Gogulu D, Uzel AJJoCPD. Efficacy of various intracanal medicaments against Enterococcus faecalis in primary teeth: an in vivo study. 2006;30(3):233-7.

18. Barcelos R, Santos M, Primo L, Luiz R, Maia LJJoCPD. ZOE paste pulpectomies outcome in primary teeth: a systematic review. 2011;35(3):241-8.

19. Reddy VJJotISoP, Dentistry P. Clinical and radiological evaluation of zinc oxide-eugenol and Maisto's paste as ob- turating materials in infected primary teeth--nine months study. 1996;14(2):39-44.

20. Seminario AL, Ivancaková RJAM-HK-. Early childhood caries. 2003;46(3):91-4.

21. Nadkarni U, Damle SJJotISoP, Dentistry P. Comparative evaluation of calcium hydroxide and zinc oxide eugenol as root canal filling materials for primary molars: a clinical and radiographic study. 2000;18(1):1-10.

22. Carranza F, Garcia-Godoy FJAjod. Esthetic restoration of primary incisors. 1999;12(2):55-8. 